\title{
AGING IN PRIMITIVE SOCIETIES: A COMPARATIVE SURVEY OF FAMILY LIFE AND RELATIONSHIPS
}

\author{
LEO W. SimMONS*
}

\section{INTRODUCTION}

Aging without family anchorage does not make a pretty picture anywhere in the world. Above all other institutions, the family has provided for old people chief essentials for prolonged physical existence and basic factors for social security. It has also constituted a central focus around which extra-familial securities for aging have tended to cluster.

Everywhere the human cycle begins with dependency of the young on those who are older; and it ends, if late in life, with dependency of the old on those who are younger-and with both dependencies deeply rooted in kith and kin. With rare exceptions, and despite potentials for strife and tension, family relationships are more intimate, responsibilities more reciprocal, and personal ties more long-lasting than in any other association shared generally by human beings. Sentiments about the "ties that bind," beliefs that "blood runs thicker than water," and folk-sayings like "bare is the back of the brotherless" are proverbial warnings out of human experience to those who would make a long go at life without the benefits of the family.

Such strong attachments are not proof, however, that sustaining family ties for the aging have always existed or that they will remain fixed in the social order. They can, and often do, break up easily. Long-livers in some families have shared remarkable securities, exercising powers and privileges that reached even past senility, and into the "dead-hand" prerogatives; but family forms and functions do shift and change with time and place and, not infrequently, these changes have serious consequences for the elders.

\section{I}

\section{Concepts of Aging}

\section{A. The Cultural Basis}

As we know, some of the parental protection of the dependent child is attributed to biologically determined factors, not infrequently called instincts, and believed to be inborn in the parent. However that may be, there is no evidence at all to support the position that the security of dependent elders at the hands of their descendants is insured on similar biological grounds.

* B.A. 1923, Bethany College; B.D. 1925, M.A. 1927, Ph.D. 1931, Yale University. Executive Officer, Institute of Research and Service in Nursing Education, Teachers College, Columbia University, since 1960. Author, The Role of the Aged in Primitive Society (I945); co-author, [with H. G. Wolf] Social Science in Medicine (1954). 
Nature in the raw is not found to be very supportive to the aging in any species. All the lower forms of life leave their aged forebears to shift for themselves in their extremities. In the same way, the human aged can be, and have been time without end, ignored, neglected, or even exploited by their offspring. Perhaps humans can be treated more "cruelly" by their descendants than are the aged in any other species. But this does not have to be the end-lot of man. He can become an exception to the raw law of nature. A maxim could be phrased, perhaps, that "man is the only animal that can be induced, willy-nilly, to provide amply for his grandfather." With respect to time and place, he may or may not be doing this. Wherein lies the difference? More especially, what is the chief element of contrast for oldage dependency and security in human as compared with other forms of life and, also, between different human groups?

In substance the difference is this: while human beings can be as indifferent to the dependency needs of their ancestors as any other creatures, and behave perhaps more badly about it, they can also learn, be taught, inspired, or impelled to respect, succor, and sustain their elders into late stages of senility. Moreover, these patterns of group and filial responsibility are "passed on" from generation to generation.

This learned behavior is called culture; and only man seems to have the capacity to create, to inculcate, and to transmit through the generations such an accumulative heritage. The fact that man is a culture-building and culture-bearing animal has made it possible for him to have a sustaining family life and the chance of a ripe, rewarding old age that is vastly longer than, and different from, that of any other creatures.

One example on the physical plane of the services of culture in the achievement of old-age security is what has been called the "taming" and the utilization of fire. When this strange element was brought under some control, used as a protective agent against inclement weather, made a defense against insects and animals, and became a stabilizing factor in family life-with its warm hearth, cooking place, and cozy corner-a new day had dawned for the elders. Indeed, fire was soon so closely associated with the frailties of age that when the necessity arose for relatives to abandon an old and enfeebled member (in accordance with the established customs and the hard conditions) it became a widespread practice, and a cherished rite, to leave the old man or woman with water, a supply of food, some fuel, and a lighted fire.

There are equally striking examples of culturally derived securities for aging in the creation of interpersonal and group responsibilities, especially those involved in the family. Instances of such are customs and rules obligating family members to respect, obey, and assist their elders. Property rights in the hands of the head of the household found firm and lasting roots in the family. Last words and testaments of old people became binding commitments on their children. Piety for ancestors linked up with worship of the gods. It is clear to see how such social developments 
served as bulwarks for aging, especially as they centered in and clustered around family situations.

As we reconstruct in our minds the manifold safeguards for aging that have been created within the family and the social order, we need to keep before us the fact that such securities are never guaranteed permanently by nature or any other power. It is a reasonable premise that every one of them can be lost again. It probably is not even sensible to regard old age security as a "chief end of human societies," as compared, for example, with motivations for the "survival of the species." It is more plausible to view the old age securities as "by-products" of a people's strivings. It would be difficult to demonstrate, even, that securities for the aged are chief ends of family functions. It is too much to expect the family to break step with the pace and direction of change in other parts of the social order. In short, securities for aging, even in the family, can be no more stable than are the social forces that create them. And these forces generally are the consequence of social strivings for ends and goals other than those of the aged. But what, after all, are the special interests and needs of those who are aging?

\section{B. Needs, Interests, or Motivations}

In a broad-gauged perspective on aging, what have older people seemed to want out of the rest of life? Their strivings make better sense when their purposes or motivations are properly perceived and understood. The interests of the aging can be classified to advantage in two general categories. There are first the easily recognized instrumental necessities and objectives that constitute immediate goals and make sense of the routine endeavors of the aged in a particular setting. Secondly, there are certain more fundamental needs and incentives that may be regarded as underlying drives or "main-springs" which impel the continued strivings of older persons everywhere.

A distinguishing characteristic of what we call the instrumental needs is that they constitute easily identifiable specifics (entities, services, skills, functions, relationships, and so on) that are recognized as pertinent to the welfare or well-being of the aged; that serve as means for the fulfillment of the more basic needs or incentives of old people in general; and that are available or producible by the society within which an older person lives. Any attempt at a full cataloguing or comprehensive classification of these instrumental needs would be futile, and perhaps impossible, because they differ from culture to culture and change over time in the same culture. A few examples, drawn chiefly from our own contemporary society, will be sufficient for our purpose.

A recent report by the Federal Council on Aging begins with a "Summary Review of Situation and Certain Needs" of our senior citizens. After calling attention to the fact that one-twelfth of our population is 65 or older, and that there really exists no "average" older person and no "uniform list of needs and wants," the Council describes "certain problems that are found to occur more often or with 
greater intensity among older individuals."' These problems or needs are presented roughly in this order: employment, income maintenance, health and medical care, housing, family ties and relationships, education for aging, and social provisions or services for various and manifold functions too numerous for inclusion here.

It is important to note that such lists of instrumental needs are oriented to a particular society and its social and cultural endowments. The instrumental needs vary widely from group to group and from culture to culture. Cash income, for example, would be meaningless to a people who engage only in barter.

Among many peoples in primitive and historical settings we have looked for the basic and recurrent interests of older persons. What do they want fundamentally; or what is the nature of the primary strivings that carry them on into senescence?

There are many ways to slice motivation in attempts to identify its chief components. It turns out, as we see it, that the primary interests of old people, or the common denominators in the goals of aging everywhere, can be summed up pretty well in a five-fold way:

I. To live as long as possible, or at least until life's satisfactions no longer compensate for its privations, or until the advantages of death seem to outweigh the burdens of life. Barring the burdens, life generally remains precious up to or near its end.

2. To get more rest; or, better stated, to find some release from wearisome exertion at the humdrum tasks and to have protection from stressful exposure to physical hazards-opportunities, in short, to safeguard and preserve the adaptive physical energies. Old people need to hoard their diminishing resources.

3. To safeguard or strengthen any prerogatives acquired in earlier life such as skills, possessions, rights, authority, and prestige. The aged want to hold on to, and they zealously guard, their seniority rights.

4. To keep up active participation in the affairs of life in either operational or supervisory roles, almost any sharing in group interests being preferred to idleness on their part and indifference on the part of others. "Something to do and nothing to be done" perhaps sums it up.

5. Finally, to withdraw from life, when the time is ripe and necessity requires it, as honorably and comfortably as circumstances permit, and with maximal prospects for an attractive hereafter.

These five fundamental interests-longer life, release from exhausting physical effort, social prerogatives, some kind of continuing participation, a timely and honorable closure-can be further reduced, reasonably well, into the two words, influence and fulfillment. These terms appear more apt than does the word security, although they, of course, involve some security.

While those needs of persons aging past their prime which we have classified as

${ }^{1}$ Federal Council on Aging, Programs and Resources for Older People, Report to the President I, 2 (I959). 
instrumental were observed to vary widely from culture to culture, the needs that are classified as fundamental ones appear to be universal in scope.

But in either case, whether instrumental or fundamental, all the goals are socially and culturally conditioned. They involve accumulated attitudes and sanctioned obligations on the part of group members toward aged incumbents and corresponding attitudes and obligations on the part of the elders to maintain their positions in the group and to exercise their rights and duties. This calls, of course, for an adaptive social process with respect to aging on the part of both the individual and his group.

\section{Process of Adjusting}

Deliberations on aging in society, and in family situations, could and probably should begin and end on the concept of adjustment or, better, adjusting. Some kind of balance has to be maintained on the one hand between family situations and society in general and between the interests of younger members of the family and its elders on the other hand. Focused attention on any one of these four components should be within a context that reflects the other three.

The chief means of security and success in aging lie in expedient adjustments to other persons and to the social system within which one lives. These adjustments constitute essentially a two-way relationship. On the one side, the environment must permit successful aging and the culture must provide for and sustain it. On the other side, the aging person must fit himself to and fulfill his functions within the familial or social settings. Thus a good old age must be active and adaptive to as near the end of life as possible. In other words, anyone's power and security in old age must rest more and more on his or her social prerogatives with their recognized duties, rights, and privileges. To put the matter somewhat bluntly, a satisfactory old age depends primarily upon the amounts of persuasion and coercion that may be exerted upon the younger and stronger persons to serve and pay homage to the needs and interests of the old and physically disabled. In broad cultural perspective, these forces and processes have operated with considerable stability and effectiveness within the family settings, but they lend themselves to successful use in many other social situations.

These adaptive processes may be initiated by the individual or by group action. On the part of the aging individual they may arise almost unconsciously, and certainly unplanned, out of existing habit patterns in the family or community; and on the part of the relevant groups they may arise "automatically" out of the prevailing folkways and mores and operate under the pressure of conventions; or they may arise out of planned programs and become embodied in legislative codes. The growth of civilizations, with respect to provisions for aging, can be characterized in part by a trend toward group-planned and legal safeguards for older people. We will see more clearly the scope and the sweep of these trends when we come to compare the adjustments of aging persons to family life in past pre-industrial societies. 
It is interesting to observe even at this point, however, that in some societies deference to, and solicitude for, aged relatives has seemed to fall squarely in line with the needs and self-interests of the younger members of the family. In such cases, youths could have said of their services to an elder, truthfully and without pathos, "Grandfather, this helps me more than it does you." In other societies, with different cultures, youths cannot see such a connection. Why? The answer lies either in the culture or the behavior of the elder-perhaps in both.

Here follows an important general principle to consider: Whenever a society and its families, with support of the prevailing culture, can create and sustain mutually supportive relationships between its youth and its elders, old age security rests on optimally firm foundations. In contrast, the severest hazards of the aged and infirm threaten to appear when older people find themselves unnecessary to, and cut off from, the interests of the young and more able-bodied upon whom they have to rely. One can speculate that a situation may develop in modern times when youth can manage very well without the contributions of the aged; but whatever widens the gap between the two will, more than likely, be at the expense of the latter, especially in the extremities of their dotage. On the side of aging, and especially in family situations, there are no good substitutes for the ties that bind youth and age in mutual interests.

\section{II}

\section{Major Family Roles and Relationships for Elders in Primitive and Pre-Industrial Societies}

It would appear that every possible approach to survival in family situations has been tried out in attempts to enrich and round off the last of life with respect to aging. The three major types of societies and cultures that differ most from our present industrial era are the so-called primitive tribes, the historical agrarian economies of the western world, and certain oriental civilizations such as China, India, and Japan. For purposes of contrast with present conditions, discussion here will deal mainly with family roles in aging as found in primitive and agrarian settings. It is within such settings that the widest range of adaptations is found in attitudes toward, and adaptations made to, the roles that older people may perform in family situations.

The farther back one goes into primitive times, the fewer old people are found, with probably not more than three or four per cent of the population who ever reached 50 years of age or over. Persons therefore gained some recognition simply on the grounds of reaching "old age," and were thereby regarded as novel or special, and perhaps endowed with some exceptional powers.

\section{A. Habitat and Subsistent Activities}

The living-together of members of three generations under various kinds of kinship systems has been a common pattern in primitive and pre-industrial societies. 
Indeed, the separation of aged and decrepit couples from younger adults did not become feasible until economic conditions permitted relative permanence of residence, a fairly constant food supply, and accessibility of the old people to their children or other relatives.

Among the most primitive tribes who wandered from place to place and survived by gathering food or hunting game, the few old people accompanied the two or three-generation family groups until they dropped by the wayside. There was nothing else to do. It was relatively late in the development of cultures before grandparents could take the risk of separation from their children and grandchildren -and hope to survive for long.

Being bound to intergenerational family groups, the oldsters made the best of the situation by means of their socially established roles, rights, and services. Along with the children, they occupied the shelter, tent, or camp more continuously than did other members of the group who foraged forth to seek subsistence. They kept the "home fire" burning, repaired structures, shaped implements or weapons, guarded and doled out supplies, minded small children and domesticated animals, and were kept continuously on the alert to help maintain the "household," often staying awake at night as "keepers" of the fires and "watchmen" for the safety of those who slept.

As capital, equipment, and enterprises became more elaborate; as economics reached the capacity for stable fishing, herding, and agriculture; as handicrafts in wood, leather, stone, and metal developed; and as residence became more comfortable and permanent, the earlier and simpler contributions of the aged in the household units expanded greatly and became far more complex in activities, supervisory functions, record-keeping, rituals, rites, etc. Even with their bent and nearly broken bodies, the few surviving old people could be prized for their nimble fingers and ready wits-and above all for their knowledge, skills, and experience. A general survey of peoples has shown that such activities and contributions have been less prevalent in the simple societies characterized by collecting, hunting, and some fishing, and more often found among herders and cultivators of the soil. As agriculture advanced, such opportunities have increased greatly. For lack of space, only brief examples are cited from widely scattered areas. As the present author has observed elsewhere:

Among the Polar Eskimo ... old couples, the infirm, and cripples went every summer to the cliffs to help cache the winter's reserve of bird meat. Old women too feeble to travel stayed indoors, attended household chores, repaired garments, tanned leather . . . and shredded with their very worn teeth the sinew of dried caribou and narwhal. . . . Old Chippewa women winnowed rice, made fish nets, tanned hides, and supervised the storing of fish and the work of the young girls. While a Chippewa family slept at night with their feet towards the coals, an old man kept watch, smoked, and fed fuel to the fire. During the day he carved ladles and pipe stems.

According to Inca law, elderly persons unfit for work should still serve as scarecrows to frighten birds and rodents from the fields. "Occupation was found for all from the 
child four years old to the aged matron not too infirm to hold a distaff. No one, at least none but the decrepit and sick, was allowed to eat the bread of idleness."2

It is clear, from more systematic analysis, that in primitive societies the aged had their fullest opportunity for extended employment among the sedentary cultivators of the soil. Here their habitat was fixed and they could shift gradually to lighter and lighter tasks; they rarely lacked for "something to do"; and they seldom suffered abrupt retirement, usually turning their hands to useful efforts until very near the end of life.

From all reports, the agrarian and handicraft economies of the Middle Ages afforded older persons similar and even greater shares of useful employment. Indeed, simple agriculture and household crafts combined have insured for individuals with even modest residues of energy and skill considerable opportunities to be useful. In this connection it is interesting to recall the more contemporary comment of a writer from a backwoods region in the Blue Ridge Mountains: "There isn't any old age problem here; we aren't modern enough to have one."

Self-employment or ancillary services in agrarian systems probably have provided the most secure and continuous occupational status that society at large has yet afforded for the majority of the aged. According to Smith,

.. . one could probably demonstrate beyond all possibility of reasonable doubt that the relative position of the aged reaches its maximum in the most highly developed rural civilizations. This is to say that when the rural mode of existence rules supreme, the lot of the aged is probably far superior to what it is in prerural (primitive) groups, on the one hand, or in the more highly industrialized civilizations, on the other.

It is true, however, that recent and more advanced developments in agriculture make for the aged a critical middle zone between old rural and modern industrial life.

\section{B. Marital Roles and Rights}

One very obvious way in which the aged have played important roles and gained considerable rights in the family has been through the status of husband or wife. Apparently throughout history and in all phases of aging from adulthood onward, the married man or woman has appeared better off than the unmarried.

Some advantages accrued to the aged spouse who was able to marry a younger and more able-bodied helpmate, either after widowhood or, where customs permit, by adding younger spouses to any already possessed. Such practices, especially marriages between older men and younger women, have been widespread in primitive societies. Where older women have been unable to marry younger mates, they have often encouraged their husbands to take on younger wives in order to lighten their

\footnotetext{
${ }^{2}$ Leo W. Simmons, The Role of the Aged in Primitive Society 83, 84, 86 (i945) (quoting I W. H. Prescott, History of the Conquest of Peru 3 I (I847)).

${ }^{3}$ Bruere, Growing Old Together, Good Housekeeping, Jan. I914, p. 86.

'Smith, The Aged in Rural Society, in Industrual Relations Resenrch Ass's, The Aged and Socrety 40, 44 (Milton Derber ed. 1950).
} 
own work loads and perhaps, also, to enhance their prestige. Instances of the union of age with youth are plentiful. An account of the custom among Omaha Indians emphasizes some of the advantages to the older partner. ${ }^{5}$

Looking at the duties and customs of the tribe, it seems that the question of domestic labor had a great deal to do with the practice of polygamy. "I must take another wife. My old wife is not strong enough now to do all the work alone," was a remark made not as offering. an excuse for taking another wife, but as stating a condition that must be met and remedied in the only way that custom permitted. The practice has been common not only in America, north and south, but in Africa where natives have a saying that "To own one wife is as big a risk as to own only one belt for palm climbing. If it breaks, you are done for."

When such reports from widely dispersed peoples have been brought together for analysis, it is clear that old men have had far greater opportunity to marry younger mates than have aging women; but their success or failure in this form of security has depended largely on the form of the kinship system and other cultural factors, such as religious beliefs, property rights, and stages of economic development.

\section{Authoritarian Rights and Roles}

More important for security of the aging than marriage to younger mates has been the possession of rank and authority within the family circle. Considerable power of parents over their children has prevailed widely in rudimentary as well as complex family systems. Vested authorities have affected a wide circle of relativesin-laws, siblings, nephews and nieces, grandchildren and others within the orbits of the kinship pattern. Such prerogatives for the aged have varied widely. Most of the data drawn from societies with matrilineal descent show that aged men and women have been able to realize considerable authority through family and kinship ties; and that women held about as high prestige as the men, sometimes higher. In patrilineal societies, on the other hand, the aged men held a great deal of family power and prestige, much more than in matrilineal groups; but old women rarely ever enjoyed similar advantages. Many striking cases could be cited of the extreme authority of aged fathers over their wives and descendants. Only one will be noted here, and that one out of antiquity. As Cicero put it: ${ }^{6}$

Appius, though he was both blind and old, managed four sturdy sons, five daughters, a great household, and many dependents; for he did not languidly succumb to old age, but kept his mind ever taut, like a well-strung bow. He maintained not mere authority, but absolute command over his household; his slaves feared him, his children revered him, all loved him, and the customs and disciplines of his forefathers flourished beneath his roof. For old age is honored only on condition that it defends itself, maintains its rights, is subservient to no one, and to the last breath rules over its own domain.

'Simmons, op. cit. supra note 2, at 178-80 (quoting G. C. Claridge, Wild Bush Tribes op Tropical AFRICA $8 \mathrm{I}-84$ (1922).

'Cicero, De Senectute 45-47 (William A. Falconer transl. I923). 


\section{Property Rights and Roles}

Property rights are a very enduring form of security for aging, and a most forceful instrument of family authority. Whenever such rights are firmly entrenched in a culture, they prove to be flexible, impersonal, and effective means for securing recognition and needed services, as well as for the satisfaction of whims. Moreover, the enforcement of property rights depends little upon the stamina of their possessors, but mainly upon the mores and the authorized agents of society who compel observance by the force of sanctions.

Probably always and everywhere there has been a marked difference between aging with and aging without property; for the requests and demands of the aged possessing worldly goods have carried far more force, even with their relatives, than have the petitions of the decrepit and poor. Even in feeble hands and in primitive societies, such vested interests have made a great difference in getting needs respected and wishes fulfilled.

The pertinent question is the extent of property rights shared by the aged in different social orders. Even in the simpler societies which are characterized by foodgathering, hunting, and fishing, some important property rights have existed and have been utilized by the aged. Among herders, property rights have generally been much more pronounced. But property rights in the hands of the aged almost certainly have had their firmest hold in the sedentary, agricultural economies, where some form of money is in common use, and where credit and trade have been regularized. Space permits giving only one example of the use of such rights by the aged.?

The aged Kafir in Africa were often rich in the labors of their women and the "sale" of their children. Kidd writes: "I once asked an old chief who had selected the site of his kraal amidst the most beautiful scenery whether he admired the view. The old man did not want to be rude, but knew not how to conceal his merriment. He went off in a hearty chuckle ... and said he chose it only that he might be able to feast his eyes on his cattle feeding and his corn ripening in the valley beneath." Shooter has commented: "We can't imagine the pride with which the old man goes from kraal to kraal, advising here, commending or reproving there, respected and obeyed everywhere; or with what complacency he looks around him from the hill on which his own habitation stands and viewing those of his children says only, "They are mine."

In a survey of property rights in primitive societies, two outstanding generalizations appear. First, sex differences are striking. Men generally have been far in the lead as property owners, but not always. Second, the rights to property by either sex in old age have varied greatly and been conditioned by environmental and cultural factors. Aged women have had some advantages over aged men in property rights among collectors, hunters, and fishers, although the difference appears less in the latter. Among farmers, and especially herders, aged men have had pronounced advantages over women. Old men also have had the advantage when property

${ }^{7}$ Simmons, op. cit. supta note 2, at 44 (quoting D. KIDD, The Essential Kafir 53 (1904), and Joseph Shooter, The Kafirs of Natal and the Zula Country 9 I (1857). 
rights have existed in land or in durable objects other than land; where techniques for mining and smelting of metals have developed; where slavery has been in force; where "money" was used as a medium of exchange; where debt-relations were recognized; where trade in place of barter has become a common practice; and under partriarchal systems of family organization. ${ }^{8}$

It is clear, however, that such findings merely show trends and do not indicate that the possession of property by the aging has been determined by any single or small number of factors. Many cultural forces, closely related and interdependent, have worked together. ${ }^{9}$

In their adjustments the mores move forward in rank, not in file, though that rank may not be without its irregularities. ... Property, law, rights, government, classes, marriage, religion-are all born together and linked together. They all march together for the sake of expediency and under the strain of consistency.

\section{E. Instructional and Recreational Roles and Rights}

Among primitive and preliterate agrarian peoples far into historical times the aging man or woman has had a distinct advantage in experience, knowledge, and wisdom. Without written records, or with poor access to them, when what was known had to be retained by memory, old people were repositories of valuable information and were in favored positions to entertain, to instruct, and to guide others towards good judgments. They were in demand for explaining puzzling phenomena, reaching decisions between "right and wrong," counseling on personal problems, and providing assurance and comfort for the fearful and distraught. Seers, medicine men, midwives, magicians, and priests were most often old men and women. They served as mediators between man and the great unknown. When faced with common perplexities and when the "need to know" was great, our forebears generally turned to the "old wise ones," preferably within the family circle. Then the elder parent or grandparent with enough experience, insight, or gumption to suggest or do something effective, or even make it appear that something could be done, had a good chance to feel useful, to act opportunely, and to be rewarded.

The old seemed especially qualified for coping with the mysterious. In addition to knowledge and experience, it was often believed that parts of their bodies had acquired supernatural force. They not infrequently claimed to be in touch with the dead and other spirits, as well as with the gods. By these powers they were believed to be able to break taboos, treat disease, drive out evil, and foretell the future. Sometimes they boasted, more often they were accused, of witchcraft and sorcery, and were feared, if not respected, for such characteristics.

${ }^{8}$ Simmons, op. cit. supra note 2 , at 36-49.

'W. G. Sumner \& A. G. Keller, The Science of Soctety 260, 502 (1927). 
F. Roles and Rights Related to Ritual and Life's Closure

The older people usually controlled the religious rites and formal ceremonies. They served as keepers of shrines, temples, and sacred paraphernalia; as officers of the priesthood; and as leaders in the performance of family or community functions associated with initiations, prayers, sacrifices, feast-days, dedications, and the launching of important or dangerous undertakings. They nearly always officiated in ceremonies linked with significant events in the family cycle-births, puberty rites, weddings, deaths, and mortuary practices. In fact, few critical occasions in life's course were not presided over or supervised by some aged and respected person.

Some societies have provided many forms of respect and "paths to prestige" for old people, while in others the opportunities have been few. Throughout, however, sex differences have been significant. In general, respect accrued to aged men especially within a patriarchal type of family organization; where herding and agriculture were the chief means of subsistence; where residence was relatively permanent, the food supply constant, and the political system well regulated; and also where property rights in land, crops, herds, goods, and even women were deeply entrenched. Aged women, on the other hand, have seemed to gain more respect in simpler societies characterized by collection, hunting, and fishing; and particularly under matriarchal forms of family organization. Their positions also have appeared to be higher among farmers than herders. Old men have been able to achieve considerable prestige, even under conditions such as mentioned above that seem to favor women; but aged women have been at a serious disadvantage where the cultural factors were weighted in favor of men. Wherever women have gained respect in old age, men also find opportunities for honor, but prestige for aged men has been no assurance of a similar status for women.

The closing scene in the drama of aging is, of course, death. A timely, honorable, and heroic departure in certain societies has enabled old people to achieve such a positive closure to life and last full measure of prestige, or has prevented them from doing so.

In primitive and early agrarian societies death often came rather abruptly. Severity of climate, shortage of food, accidents, or the hazards of disease and warfare forced weaker members to succumb. Moreover, death took children, youths, and persons in their prime more frequently than it took the old, for very few got to be old. Thus death was more commonly associated with youth than with age, and life was more often snuffed out suddenly than left to flicker and fade. As a consequence, the deaths of old people, especially those prominent for their sanctity, wisdom, or power, could take on a special significance.

Not infrequently the manner and means of an older person's departure appeared to him and to his contemporaries more significant than the necessity itself. Nevertheless, though a dignified or even glorified death for the aged became possible in some instances and nearly obligatory in others, such was not the common lot of all. The event required a favorable combination of both personal qualities and 
cultural conditions. In the majority of instances and over a wide range of cultures, death occurred in old age as a degrading experience, particularly when long delayed.

The available data leaves little room for doubt that neglect or abandonment has been a fairly frequent means of eliminating old and enfeebled persons. To move on and leave behind permanently helpless people has been the simplest, and probably the most humane, method of coping with an unavoidable necessity. In fact, many aged are reported having urged their relatives to do this, explaining how they had done it to their parents. The practice probably has existed somewhere in the history of every group. On the whole, but not always, such treatment has tended to cease under more favorable conditions. But when it has been associated with fear of the dead, and when long established through wont and custom, it has often survived long after the circumstances that required it have changed.

The taking of life, mercifully or otherwise, has also been a fairly common practice. In a systematic survey of a sample of seventy-one peoples scattered throughout the world, nearly a third carried reports of violent forms of death customarily imposed on the aged. Not infrequently relatives and friends have regarded these acts as more merciful and honorable than would be a natural death by abandonment or otherwise, and the aged are often reported as anticipating or even demanding it as their right. ${ }^{10}$

To relate just one example of many that are available, Hawkes (rgi6) has reported that the Labrador Eskimos were treated with great respect in old age; but states further, "This does not prevent them, however, from putting the old folks out of the way when life becomes a burden to them. But the act is usually done in accordance with the wish of the persons concerned and is thought to be proof of devotion." These people believed there are special heavenly compensations for dying voluntary and violent deaths. Their spirits would be transported higher up, in the vicinity of the Aurora Borealis, where they could spend their time "playing football with a walrus head," and in company with other courageous souls.

It would appear in broad perspective that abandonment, exposure, or dispatchment of the aged had their origins in dire necessity and became elaborated by cultural rituals and compensations that caused the expedients to survive beyond the conditions that created them. In many reports relatives have wished to give up the practice before the aged have been willing to forego it as a traditional right; and in some societies the recipient of the "service of closure" has insisted on the further right of setting the time, selecting the favorite offspring to accomplish the act, and specifying the manner in which it was accomplished.

The attainment of prestige by means of such a closure has depended largely on a combination of circumstances. In only about half the groups where the aged have been dispatched could reports be found indicating a distinct honor associated with the occasion. It would appear that maximum opportunities for glory in the ex-

${ }^{10}$ Simmons, op. cit. supra note 2, at 232-33 (quoting E. W. Hawkes, The Labrador Eskimo (Canada Dep't of Mines, Geological Survey, Memoir 91) I09, II7 (1916)). 
perience have required an appropriate situation plus some courage: physical condiditions that made it necessary; cultural beliefs about life, death, gods, and the hereafter that justified the deed and cushioned the blow; and precedents that ${ }^{\circ}$ prescribed the manner and delegated the proper agents to perform the deed. In addition to these, an audience was necessary and possibly a celebration attending the ceremony. Finally, the candidate needed to possess sufficient force and character to accept the challenge and the step to be taken before senility reached a state of stupidity.

Death can hardly be a stranger to the aging in any society. Every long life has had some "close calls," and part of the price of living on is to suffer the "passing" of relatives, friends, and associates. In fact, a common experience in certain phases of aging is to become preoccupied with, and perhaps to come to "terms" with, the prospects of life's closure. It actually comes daily at present in the United States for something between two and three thousand of our senior citizens.

In a society like ours that accords status to work over leisure, that prizes youth above seniority, that venerates knowledge more than experience, and (above all) abhors death, the aged and decrepit find themselves at a certain disadvantage. This is especially so when it comes to coping with a closure to their lives.

Among all peoples that we know anything about, a point is reached in agingif death is greatly postponed-when any further "worthwhileness" of life seems to be over. Then the incumbent is regarded as a surviving liability, perhaps to himself and certainly to others. Senility may be a suitable label for this state. Similar terms used in other societies are: "overaged," the "useless stage," the "sleeping period." Then, without actual closure, the prospects are uniformly gloomy. There is no question about this generalized social decision on the extremities of age; the differences arise only with respect to the point in aging at which the "useless" stage is reached. In some societies it is faced more realistically and coped with more positively than in others.

A significant fact to observe is that in all societies until modern times, the senile or "over-aged" period was not of much social importance. Few reached such a stage and almost none lasted very long in it. If the group did nothing about it, nature resolved the matter with relative dispatch. The helpless and hopeless period in age is taking on much greater importance in our civilized times, thanks to modern medical skills and life-preserving techniques. With recently developed medical and nursing provisions it is becoming, for an aged person, more difficult to die. Add to this the recognized fact that the "useless period" for a person is largely socially and culturally determined, and that it may be moved forward or delayed in years. The social fates are most unfortunate, of course, when multitudes of old people are made to feel useless relatively early in their aging and find the twilight years empty and long-lasting. Death is really, and eventually, the only solution to aging; and whether life can be made good to the last drop depends in part on how we "drop." 
III

Lessons AND Issues For MODERNS

Studies on aging in primitive, historical, and contemporary perspectives should provide opportunities for the acquirement of some wisdom for dealing with age as well as knowledge about aging. A few primer-like lessons are suggested here.

\section{A. Aging is Complex and Challenging}

For civilized man, aging is not a simple experience that one drifts into safely and copes with only if and when it comes. It must be met by "advance guards" or it may creep upon one unawares and "off guard."

Many of us face aging with two common mistakes and some poor judgment about its onset. The first mistake is to try to compare and choose between youth and age. The choice does not lie between those two; for when we have had the former, it becomes age or else. The second mistake is to regard aging as primarily a time of resting. Age for rest is only a half-goal at best. The endeavor and the strategy of adjusting had better go on, refined and intensified, for to stop is to go down.

Then there is the delicate judgment of deciding when to be old. Everyone knows that it is not a simple matter of chronology, yet we let the calendar be a great bugaboo, and "beat about it" and debate with ourselves on whether it's "now" or "later." "Being one's age" is not as simple, now that we have a calendar, as it was for our primitive forebears without any reliable records of time.

\section{B. A Curse or Challenge?}

The second lesson is that aging can be "good" or "bad," and that when it is good it generally is more of an achievement than a gift. Anyone must, of course, get to be old before he can make aging something good, and most people have never been able to get there. Here is a surprise in studies of aging: some societies solved the problems of successful aging for a few persons long before they could assure any old age at all for the many. The secret of success was for a person to find for himself a place in his society where he could age with participation and fulfillment, and to keep at it tactfully until as near the end as possible. Aging must be gamey up close to the end to remain very good.

\section{Individuality}

A third lesson about aging is the fact of wide individual differences. It is a grosser error to stereotype aging than childhood. Scripture's dictum on childhood is a "straight way" and a "narrow course." It could have pronounced for aging a varied way and a broad course. It is amazing how many different ways of aging have been tried out with reasonable success in family life. Suppose we look again for a moment at the differences in aging in our contemporary society: some of our aged are between $6_{5}$ and $70 ;$ most are over 70 . Some are working; most are not. 
Some are living with spouses; most are not. Some live alone; most do not. Some have adequate income; most do not. Some are without Social Security benefits; most are not. Some receive private pensions; most do not. Some receive Social Security and private pensions; most do not. Some of the aged have good health; most do not. Some have hospital insurance; most do not. Some aged have moved away from the state in which they were born; most have not. Some live in rural areas and villages; most do not. Some are childless; most are not. Some feel neglected by their children; most do not. Some achieve a reconciled life and a dignified death; most do not. $^{11}$

\section{Stable Patterns of Adjusting}

There are patterns of participation for the aging that become relatively fixed and dependable in stable societies. These patterns may suffer disruption, however, in periods of rapid social change. The stable societies provide a structured framework for personal participations that are status-and role-defined, sex-typed, aptitude-rated, and age-graded. If the pattern stays fixed for long periods the aging get a lifetime to fit in and entrench themselves. In the long, steady strides of the social order the aging get themselves fixed and favored in comfortable saddles; but when conditions become unstable, and change in the social order makes for a galloping pace, the old ride on for a fall and the more youthful leap into their seats.

Change is perhaps the greatest challenge of all to the aging, for even family ties and positions are not fixed and infallible. In fact, they often become fragile and unexpectedly brittle. Moreover, the forms and functions of family life are found to shift to and fro with the sweeping tides of social change, and often with disruptive effects upon the superannuated. This fact of change alone makes it certain that there can be few permanent solutions to aging in family settings or anywhere else.

${ }^{2}$ Adapted, with items added, from Cohen, Income Adequacy and Pension Planning in the United States, in International Ass'n of Gerontologx, Aging and Social Health in the United States AND EUROPE 6 (1959). 